\title{
DISIDENCIAS DE PEDRO ABELARDO
}

\author{
Mariano Brasa Díaz \\ U.A. Madrid
}

Galorum Socrates, Plato maximus Hesperiarum, Noster Aristoteles, logicis quicumque fuerunt Aut par, aut melior; studiorum cognitus orbi Princeps; ingenio varius, subtilis et acer; Omnia vi superans rationis, et arte loquendi Abaelardus erat...

Cuando en el otoño de 1142, Pedro el Venerable, el gentleman de los místicos medievales, redactaba este célebre epitafio para la tumba de Abelardo en El Paráclito, incluso cediendo a la sugestión del énfasis, común a la literatura epigráfica, expresaba indudablemente la convicción y su admiración y la de sus contemporáneos, por la más grande y más discutida figura de la historia intelectual europea del siglo XII.

Abelardo había caído, es cierto, como un gigante herido, bajo la «artillería pesada» de las apremiantes acusaciones de san Bernardo. Cansado de años y de desventuras, se había retirado de la lucha que le había visto comprometido en un ambicioso programa de renovación de la cultura durante un largo período de más de treinta años. Pero precisamente - en este contexto y en este clima calentado de polémicas y de contrastes, impelido hasta el odio ideológico, el elogio del abad de «Cluny venía a asumir el significado de una valoración precisa y tendía a restablecer el equilibrio en el juicio sobre Abelardo, en clara y evidente oposición con la actitud negativa del abad de Clairvaux al que la excesiva intransigencia por la defensa de la tradición y el temor de ver contaminada» la pureza de la fe por la dialéctica de Abelardo, no le dejaban ver con claridad. Eran ruidos que le impedían oír con nitidez la nueva sinfonía que su adversario quería componer; era una mezcla de olores que no le dejaban percibir el buen olor de la dialéctica, de la buena, de la peripatética.

Las dos tentaciones, o mejor todavía, las dos sugestiones - rechazo de la tradición y aplicación de la dialéctica a la verdad de la fe-,están constantemente presentes en la 
experiencia abelardiana, pero sus efectos, no son tan nefastos como temía san Bernardo sino más bien constituyen el soporte del nuevo e inimitable estilo de vida y de pensamiento de Abelardo.

Toda la vida y la obra de Abelardo pueden, de hecho, ser clasificados bajo el rótulo disidencias, como aparece en las páginas de su Historia calamitatum que constituye todo un documento de singular interés histórico y humano y debe ser considerado como una de las más grandes y originales autobiografías de la literatura universal. ${ }^{1}$ Esta Historia calamitatum, estas «memorias» de Abelardo, son las que van a servir de base para este trabajo. Leer la Historia calamitatum de Abelardo siempre sugiere algo nuevo. Hay rasgos que escapan a una primera lectura y que te vas encontrando con ellos según vas leyendo la obra una, dos, tres veces. Hoy, al leer de nuevo la obra de Abelardo, se me ha ocurrido destacar este rasgo de disidente, de inconformista, de no sujetarse a lo establecido.

El primer rasgo de ruptura con la tradición Abelardo lo lleva a cabo siendo un adolescente. Era un estudiante que había renunciado a la carrera militar y a los derechos de primogenitura, porque había saboreado los primeros frutos embriagadores del árbol de la ciencia. La dialéctica la encontraba agradable al paladar. Era algo que gustaba y creía que podía sacar partido de ella. ¿Por qué no cambiar los planes de estudio? ¿Por qué continuar con las artes del trivium desangeladas, cuando Aristóteles está llamando a las puertas de las escuelas? Abelardo lo había oído y quiso seguir hasta el final con lo que había comenzado a gustar:

«Por mi parte, cuanto más fácilmente progresaba en los estudios literarios, tanto más más ardientemente me entregaba a ellos, hasta ser seducido con tanta pasión que cediendo a mis hermanos el fasto de la gloria militar, la herencia y mis derechos de primogenitura, abandoné completamente la corte de Marte con el fin de elevarme hasta el seno de Minerva. Y puesto que entre todas las disciplinas filosóficas preferí las armas a la dialéctica, cambié con ella las armas de la guerra y prefería a los trofeos de las batallas, las luchas de las disputas. Me convertí así en un émulo de los peripatéticos y recorrí, disputando, las diversas provincias, donde quiera estuviera en vigor el estudio del arte de la dialéctica». ${ }^{2}$

La dialéctica era entonces la disciplina de moda y se identificaba con la lógica o con la filosofía en general. A menudo se reducía a una especie de ludus mentis, con fin en sí misma. Con Abelardo, conocido con terminología medieval, como «caballero de la dialéctica», esta disciplina volverá a ser la magistra disserendi, como lo había sido para Boecio después de su contacto con los primeros libros del Organon del viejo Filósofo. A partir de entonces hablamos de logica vetus y hablamos también de la primera entrada de Aristóteles en el mundo occidental. Hecho importante y a tener muy en cuenta de Abelardo, será una

1 Cfr. Abelardo, Historia calamitatum, ed. crítica de J. Monfrin, Paris, J. Vrin, 1967. En adelante citaré esta edición. La traducción de los textos es mía.

2 Abelardo, Historia calamitatum, ed. cit., líneas 19-30. 
dialéctica renovada y agresiva que llevará consigo el desconcierto y una ráfaga de revuelta anti-tradicionalista a la más prestigiosa de las scholae de Francia y no dudará en penetrar incluso en el templo de la Fe, dando como resultado el gran conflicto entre dialéctica y mística.

Pero sigamos los pasos del joven Abelardo, del estudiante, del clérigo - término que no significa necesariamente sacerdote o monje. El clérigo aparece con frecuencia al lado de los grandes grupos sociales de la época. Es el descendiente y el heredero directo de un linaje especial que lo constituyen los intelectuales. Es el representante de la cultura. Este intelectual se anuncia en la Alta Edad Media, se desarrolla con las escuelas del siglo XII y se perfeccionará a partir del siglo XIII con las universidades. Nuestro clérigo que vive los últimos veinte años de un siglo y los cuarenta primeros del otro, frecuenta los mayores centros de la cultura occidental del siglo XII, desde que un buen día saliera de la Palet natal, en la Bretaña francesa. ${ }^{3}$ Buscaba la sabiduría, pero no sabía a dónde iba a llevarle. Quería saber y abandona la lucha con las armas, y al ir aprendiendo, al aumentar su bagaje intelectual, creció en él ese espíritu belicoso que lleva dentro y comenzó una lucha que iba a ser sin tregua, con el arma de la dialéctica. Pero no renuncia a su fe.

La primera etapa de este itinerario, la célebre schola verbalista de Roscelino en Tours y en Loches, la conocemos a través de un testimonio de Otón de Frisinga ${ }^{4}$ y una carta del mismo Roscelino descubierta en $1849^{5}$ que el maestro «verbalista» dirige a su discípulo Abelardo y que éste silencia total e intencionadamente en la Historia calamitatum. El motivo del silencio es debido, casi con toda seguridad, al desdeño que provocó en Abelardo esta carta llena de vulgares injurias, que dirige el viejo maestro hacia el año 1120 , al término de una fuerte polémica sobre problemas de teología trinitaria. Pero yo creo que lo que llevó a Abelardo a no mencionar siquiera esta carta, son las ofensas contra Eloísa a la que llama prostituta y ramera, scortum et meretrix. ${ }^{6}$ Sólo podemos preguntarnos cómo, cuando Abelardo escribía su autobiografía entre 1134 y 1135, persistía todavía en su ánimo ese

3 Pedro Abelardo hijo de un noble caballero bretón, Berengario, vasallo del duque de Bretaña, nació en 1079 en el castillo de Palais o Pallet. El castillo, situado a pocos kilómetros al noroeste de Nantes, era llamado en la antigua toponimia galo-romana Palatium, y de aquí surgió el apelativo de Philosophus o Peripateticus Palatinus atribuido a Pedro Abelardo por su discípulo Juan de Salisbury y otros escritores contemporáneos.

4 Otón de Frisinga, Gesta Frederici I Imperatoris, Lib. I, cap. 47, ed. G. Pertz, en M. G. H., SS t. XX, Hannoverae 1868, p. 376. Aquí se atestigua que Abelardo tuvo como primer maestro a Roscelino, el iniciador del nominalismo: «Habuit primo praeceptores Rozelinum quendam, qui primus nostris temporibus in logica sententiam vocum instituit».

5 Cfr. V. Cousin, Petri Abaelardi Opera, t. II, Paris, 1859, pp. 802 ss; P.L. t. 178, pp. 357 ss. En esta carta Roscelino reprocha a Abelardo el haberse olvidado de los beneficios recibidos a puero usque ad iuvenem sub magistri nomine y le recuerda su enseñanza en Tours y en Loches, ubi ad pedes meos, magistri tui discipulorum minimus, tan diu resedisti, P.L. t. 178, p. 360.

6 En la carta Roscelino defiende su doctrina trinitaria y arremete contra Abelardo con tal violencia de lenguaje e ironizando de tal manera contra Abelardo al que llama «Pedro Incompleto» por su mutilación e hipócrita y calumniador por el contenido de su carta. Pero lo que de verdad debió herir la sensibilidad de Abelardo y lo que le indujo a vengarse con el silencio, fue la grave ofensa contra Eloísa a la que llama, sin medias tintas, scortum y meretrix. Cfr. Epist.., P.L. t. 178, p. 370. 
rencor que le llevaba a borrar para siempre de su recuerdo el nombre de su antiguo maestro ya desaparecido hacía una década.

Después del periodo pasado como discípulo de Roscelino, entre 1094 y 1098 y otras experiencias, completa su peregrinar joven por varias escuelas de Francia ${ }^{7}$ y hacia el año 1100 , Abelardo, a sus veinte años, apostó decididamente por París, considerada entonces como caput scientiarum y roca firma de la dialéctica. Y fue aquí, en París, donde comenzó a frecuentar las lecciones de Guillermo de Champeaux. Todo era paz, conformismo, un estar de acuerdo general y un aceptar todo porque, siguiendo la vieja máxima pitagórica, el maestro hablaba, decía y no se equivocaba. Pronto esta atmósfera conformista se contamina, la paz se turba y hay intentos de contradecir lo que maestro había dicho.

«Finalmente llegué a París, donde ya esta disciplina - la dialéctica- florecía con pujanza en la escuela de mi preceptor Guillermo de Champeaux, célebre entonces en esta clase de enseñanza y con merecida fama. Permanecí con él breve tiempo, primero a gusto, después molestísimo, al haber intentado refutar algunas de sus opiniones y osar contradecirlo muy a menudo, apareciendo a veces como vencedor en la disputa. Lo que, precisamente aquellos, entre los discípulos, que eran tenidos como más inteligentes, soportaban con tanto mayor desdén cuanto menos me avaloraban por mi edad y por el tiempo de estudio».8

Un segundo y clamoroso gesto de disensión va a tener lugar cuando se produce una protesta, un movimiento, una revuelta contra ipse dixit y contra la «dictadura intelectual» del magister en la escuela.

En esta «impetuosa ruptura de un orden establecido» ${ }^{9}$ hay algo más que la orgullosa presunción de un joven dialéctico. Es el primer resurgir, confuso todavía, de un orden nuevo y precisamente será ésta la razón profunda y auténtica, y no sólo el orgullo, como reconoce el joven bretón, lo que inducirá a Abelardo «a aspirar, siendo todavía joven, al gobierno de una escuela». ${ }^{10}$

Una vez escogida la sede, en esta caso la ciudad real de Melun, una de las residencias del rey Felipe I, Abelardo debía superar no pocos obstáculos para obtener una licentia -docendi. Entre estas trabas estaba el gran obstáculo de las fraudulentas maquinaciones, como el propio Abelardo las llama, «[...] quibus potuit modis latenter machinatus est ut

7 «Proinde diversas disputando perambulans provincias, ubicumque huius artis (dialecticae) vigere studium audieram, peripateticorum emulator factus sum», Historia calamitatum, ed. cit., 28-30.

8 «Perveni tandem Parisius, ubi iam maxime disciplina hec florere consueverat, ad Guillhelmum scilicet Campellensem perceptorem meum in hoc tunc Magisterio re et fama precipuum; cum quo aliquamtulum moratus, primo ei aceptus, postmodum gravissimus extiti, cum nonnullas scilicet ejus sententias refellere conarer et ratiocinari contra eum sepius aggrederer et nonnumquam superior in disputando videret. Quod quidem et ipsi qui inter conscolares nostros precipui habebantur tanto majori sustinebant indignatione quanto posterior habebar etatis et studii tempore», Historia calamitatum, ed. cit., 31-41.

9 F. Alessio, «Abelardo», en I protagonisti della storia universale, vol. IV, Milano, C. E. I., 1967, p. 425.

10 «...] ad scolarum regimem adolescentulus aspirarem», Historia calamitatum, ed. cit., 46-47. 
priusquam a suis recederem scolis[...]» (Hist. cal., lin., 51-51), de un maestro Guillermo empeñado, por todos los medios, en romper la carrera que Abelardo estaba decidido a correr hasta llegar a la meta. Al final, el poderoso maestro debió declararse derrotado, mientras que su joven antagonista, después del primer triunfo obtenido en Melun, trasladaba su escuela al castillo de Corbeil, ad castrum Corbelii, en las cercanías de París, con la precisa y declarada intención de crear un obstáculo en el lugar justo de intriga y de provocación, a la escuela parisina donde estaba enseñando el maestro Guillermo de Champeaux.

El duelo entre Abelardo y Guillermo, interrumpido por una imprevista enfermedad de Abelardo, un agotamiento provocado por su «inmoderada» pasión por el estudio, «ex inmmoderata studii afflictione correptus infirmitatem coactus sum repatriare, et per annos aliquot a Francia remotus», ${ }^{11}$ continuó años después, hacia 1108 , cuando el joven dialéctico, de vuelta de Bretaña donde se había recluido para recuperar las energías físicas perdidas, volvió a sentarse en los bancos de la escuela del maestro Guillermo. El gesto de Abelardo era lo más parecido a una provocación y la tormenta de un nuevo enfrentamiento estallaría de un momento a otro. Era inevitable:

«Entonces yo, de vuelta a la escuela de Guillermo para seguir sus lecciones de Retórica y tras acaloradas disputas, le obligué con argumentos evidentes a modificar, e incluso a demoler, su antigua doctrina sobre los universales [...]. Y puesto que la doctrina sobre los universales constituye siempre un problema fundamental y muy difícil para los dialécticos, tanto que el mismo Porfirio en la Isagogé, tratando de los universales, no osó resolverlo y se contentó con decir: "Altissimús enim est hujusmodi negotium", sucedió que cuando el maestro Guillermo consiguió abandonar, mejor, fue obligado a abandonar su opinión, su enseñanza fue tan desangelada, tan negligente, que a duras penas podía pensar en exponer las otras partes de la Dialéctica, como si el arte de la Dialéctica sólo consistiera en el problema de los universales». ${ }^{12}$

El resultado final de la lucha fue que Guillermo, vencido y humillado, buscó refugio primero, en un convento y, después, abandonó la peligroso carrera de magister de dialéctica y prefirió la más segura escuela episcopal de Châlons-sur-Marne, donde murió siendo obispo de Châlons en 1120. Antes hubo más polémicas, podemos hablar casi de innumerables polémicas y una última andanada, esta vez de fuego, del maestro Guillermo de Champeaux que obligó a Abelardo a retirarse de nuevo a Melun y después a establecer su

11 Abelardo, Historia calamitatum, ed. cit., 66-68.

12 «Tum ergo ad eum reversus ut ab ipso rethoricam audirem, inter cetera disputationum nostrarum conamina antiquam ejus de universalibus sententiam patentissimis argumentorum rationibus ipsum commutare, immo destruere compuli [...]. Et quoniam de universalibus in hoc ipso precipua semper est apud dialecticos questio ac tanta ut eam Porphirius quoque in Ysagogis suis cum de universalibus scriberet definire non presumeret dicens "Altissimum enim est Hujusmodi negotium", cum hanc ille correxerit immo coactus dimiserit ad cetera dialectice vix admitteretur quasi in hac scilicet de universalibus sententia totam hujus artis consisteret summa». Historia calamitatum, ed. cit., 80-85; 91-100. 
escuela en la colina de Santa Genoveva, fuera de los muros de la ciudad: «extra civitatem in monte Sancte Genovefe scolarum nostrarum castra posui [...]».

Para poner el colofón y sellar su victoria sobre el maestro Guillermo Abelardo escoge dos versos de la Metamorfosis de Ovidio: «Si queritis hujus/ Fortunam pugne, non sum superatus ab illo». ${ }^{13}$ No había sido superado por su contrincante. Si el joven dialéctico calla, hablan los hechos.

Tal y como acaba la polémica de Abelardo con Guillermo de Champeaux parece como si de una guerra se tratara. Es un modo perentorio y cuasi-militar. No se ha llegado al pacto. No se ha firmado la paz. Ha habido vencedor y vencido. Vencedor, Abelardo, está dispuesto, con la fuerza que le da la victoria, a invadir un nuevo territorio. Esta vez va a adentrarse en un campo inexplorado todavía por el joven dialéctico: la ciencia teológica que, por aquellos años «estaba formándose, no sin graves dificultades, y que era dominada por un nombre, el del viejo Anselmo de Laon: ${ }^{14}$

«En materia teológica, tenía gran fama y autoridad el maestro Anselmo de Laon. Me acerqué entonces a este anciano que debía su fama más al largo tiempo que llevaba enseñando que a su ingenio o a su memoria. Si alguien se acercaba para consultarle una duda sobre algún problema concreto, se volvía más inseguro que antes. La duda era mayor, redibat incertior. Era admirable a los ojos de los oyentes, pero nulo ante las preguntas. Poseía un lenguaje brillante, pero pobre de conceptos y vacío de contenido. Era como el fuego que cuando se enciende llena la casa de humo y no produce luz o como un árbol que al que lo ve de lejos le parece lleno de hojas y frutos, sin fruto, vacío. Al percatarse de esto no permaneces muchos días ocioso a su sombra». ${ }^{15}$

Anselmo de Laon era considerado entonces como «el magister divinitatis por excelencia», ${ }^{16}$ pero a los ojos de Abelardo aparecía como el típico representante de los viejos teólogos, incapaces de comprender las nuevas exigencias de la ciencia religiosa de la época, sacudida por inquietudes racionalizantes y no satisfecha con el tradicional fideísmo acrítico. De aquíla injusta e inmerecida «intronización» y las abiertas y ásperas críticas al método de enseñanza del maestro Anselmo que levantaron indignaciones y protestas entre los numerosos discípulos, los cuales,

13 Ovidio, Metamorphosis, XIII, 89-90: Historia calamitatum, ed. cit., 151-152.

14 P. Wolf, Storia e cultura del Mediaevo dal secolo IX al XII, trad, it. de M. Valbonesi, Bari, Laterza, 1969, p. 251.

15 «In hac autem lectione magister ejus Anselmus Laudunensis maximam ex antiquitate auctoritatem tunc tenebat[...]. Accessi igitur ad hunc senem, cui magis longevus usus quam ingenium vel memoria nomen comparaverat. At quem si quis de aliqua questione pulsandum accederet incertus, redibat incertior. Mirabilis quidem in oculis erat auscultatium, sed nullus in conspectu questionum. Verborum usum habebat mirabilem, sed sensum contemtibilem et ratione vacuum. Cum ignem accenderet, domum suam fumo implebat, non luce illustrabat. Arbor ejus tota in foliis aspicientibus a longe conspicua videbatur, sed propinquantibus et diligentius intuentibus infructuosa reperiebatur[...] Hoc igitur comperto non multis diebus in umbra ejus ociosus jacui». Historia calamitatum, ed. cit., 161-174; 180-186.

16 M. de Wulf, Histoire de la Philosophie Médiévale, Louvain, Inst. Sup. de Philosophie, 1. a ed. 1900, p. 177. 
en defensa del maestro, desafiaron a Abelardo a que sostuviera una lectio pública como prueba de su capacidad y presentara a examen su nuevo método del que se sentía tan seguro y que contraponía al tradicional seguido por el maestro Anselmo.

Como argumento de la inusitada lección se escogió la oscurísima profecía de Ezequiel: «Et consenserunt omnes in abscurissima Hiezechielis prophetia», ${ }_{17}^{17}$ que el filósofo de Palet, improvisándose exegeta y teólogo a la vez, comentó durante varios días tan brillantemente que suscitó la sorpresa y la admiración general.

Abelardo inició así un curso de exégesis en Laon. Pero dos discípulos del viejo maestro Anselmo, Alberico de Reims y Lotulfo de Lombardía que serán luego los enemigos más encarnizados de Abelardo, instigaron a su antiguo maestro para que interviniera mediante una prohibición, para impedir que Abelardo pudiera continuar sus lecciones. Era, de hecho, un gran escándalo el que alguien osara asumir sine magistro, la enseñanza de la Sagrada Escritura, «[...] et quod sine magistro ad magisterium divinae lectiones accedere presumpsissem ${ }_{.}^{18}$

Pero mientras para unos el sine magistro se convertía en la mayor acusación contra Abelardo, para el maestro de Palet era una de sus mayores títulos de gloria. Este autodidacta en la historia del pensamiento medieval no tiene maestros, y digo esto aun a sabiendas de que tuvo como maestros de dialéctica a J. Roscelino y a Guillermo de Champeaux y a Anselmo de Laon como maestro de teología, pero tanto Roscelino, como Guillermo y Anselmo se convirtieron para Abelardo en punto de mira contra los que dirigir los dardos de su dialéctica. Fue un émulo y no un discípulo. En cambio, Abelardo se convierte en maestro incomparable, dotado de una fascinadora elocuencia, de una irresistible fuerza dialéctica y de una enorme cultura, como sabemos por los testimonios de sus mismos adversarios.

El período más brillante del magisterio y de la vida de Abelardo coincide con su vuelta triunfal a París, después de la «defenestración» de la escuela de Laon por los discípulos del viejo maestro. Son los años de gloria entre 1114 y 1118 en los que enseñó en la escuela de Nôtre-Dame, donde había enseñado Guillermo de Champeaux y que iba a convertirse en algo así como un puerto de llegada al que acudían los estudiantes de Europa atraídos por la luz de su faro.

Por los testimonios de la época y, sobre todo por la Epistola de Fulco de Deuil, sabemos que acudían a la escuela de Abelardo muchos estudiantes de todas las regiones de Francia, de España, de Inglaterra, de Flandes, de Germania e incluso de Roma:

«Roma que fue en tiempos la maestra de todas las artes, te enviaba a sus alumnos para que tú los instruyeras, demostrando con esto que tu sabiduría era superior a la suya. Ni la distancia, ni la altura de las montañas, ni la profundidad de los valles, ni los caminos llenos de peligros e infectados de ladrones, impedían a los discípulos llegar hasta ti. La multitud de los jóvenes ingleses no temían ni la travesía, ni las tempestades del mar: con sólo oír su nombre, menospreciaban cualquier peligro para correr junto a ti. La lejana Bretaña te enviaba sus jóvenes rubios; los de Anjou

17 Abelardo, Historia calamitatum, ed. cit., 203-204.

18 Ibidem, 684-686. 
dominaban su bravura nativa a tus enseñanzas; los de Poitou, los de Gascuña, los Ibéricos, los Normandos, los Flamencos, los Teutones y los Suevos rivalizaban por alabar, exaltar y celebrar tu ingenio. Los habitantes de París y de todas las regiones galas, próximas o lejanas, estaban sedientos de tus enseñanzas y pensaban que no podían ser expertos en alguna disciplina si no estudiaban en tu escuela. Fascinados por la lucidez de tu ingenio, de la gracia y eficacia de tu discurso, de la profundidad de tu ciencia, acudían a ti como a la más pura fuente de la filosofía». ${ }^{19}$

Abelardo ha caído como dentro de un torbellino de orgullo. Se consideraba como el único filósofo del mundo. ${ }^{20} \mathrm{Su}$ tensión intelectual ha llegado al máximo. De pronto cambia su destino. El homo carnalis tiende una fatal insidia al homo intellectualis.

Hasta ahora, y estamos en 1118, cuando Abelardo contaba treinta y nueve años, el joven dialéctico había vivido continentissime, según sus palabras. ${ }^{21} Y$ en cuanto al amor, al haber sido educado en el misogenismo clásico, propio de la tradición filosófica, no conocía más que los versos un tanto licenciosos del Ars amandi de Ovidio y tal vez las historietas lascivas de las canciones de los goliardos y de los cortesanos de la época. Pero la pasión amorosa que antes había volado por su fantasía con la lectura de los poetas, sin perturbar lo más mínimo su espíritu, ahora la siente dentro de sí como algo que no puede dominar. El rostro siempre agradable de una joven, ya no el de Minerva que lo prefiere al de Marte, sino el de una criatura real, llena de juventud, y como el propio Abelardo, amante de la sabiduría, siempre con ganas de saber más, comienza a turbar sus sueños y también sus meditaciones filosóficas. Estamos en vísperas del romance de amor más noble, más entregado y más intelectual de la Edad Media: el romance de amor entre Abelardo y Eloísa. Era un amor imposible en aquel contexto. Al final será un tráfico romance de amor:

«Vivía en la ciudad de París una joven de nombre Eloísa, ${ }^{22}$ sobrina de un canónigo llamado Fulberto que, cuanto más la quería, tanto más diligentemente trataba de instruirla en todo saber literario. La joven, aunque no era la primera por sus encantos femeninos, superaba a todas, en cambio, por su vasta cultura literaria, ${ }^{23}$ y esta dote,

\footnotetext{
19 Fulco de Deuil, Epistola consolatoria ad Petrum Abaelardum, P.L. t. 178, pp. 371-255.

20 «...] cum jam me solum in mundo superasse philosophiam estimarem [...]», pp. 254-255.

21 «...] qui antea vixeram continentissime». Historia calamitatum, ed. cit., p. 257.

22 - No sabemos nada del padre, del lugar y de la fecha de nacimiento de Eloísa. De la madre sólo conocemos su nombre, Hersenda, recordado en una necrología latina de El Paráclito el uno de diciembre: Hersindis, mater dominae Heloisae, abbatissae nostrae. En la misma necrología con fecha 26 de diciembre se lee: Hubertus -el copista escribe Hubertus por Fulbertus - canonicus dominae Heloisae avunculus. Fulberto era por lo tanto tío materno (avunculus) de Eloísa y su madre, Hersenda, hermana del canónigo Fulberto.

23 Sobre la cultura literaria de Eloísa dan fe el testimonio nada sospechoso de Pedro el Venerable, Epistola $21 ;$ P.L. t. 189, p. 347, y sobre todo las cinco cartas que conservamos de ella, cuatro dirigidas a Abelardo y una a Pedro el Venerable, P.L. t. 178, pp. 181, 191, 213, 677, y P.L.t. 189, p. 427. Abelardo en la Epistola ad Virgines Paraclitenses de studio litterarum, P.L. t. 178, p. 333, afirma que Eloísa conocía, además del latín, el griego y el hebreo: «Magisterium habetis in matre... quae non solum Latinae, verum etiam Haebraicae quam Graecae non expers litteraturae, sola hoc tempore illam trium linguarum adepta peritiam videtur».
} 
que es muy rara en las mujeres, le confería un particular atractivo y le había hecho famosísima en todo el reino. Encontrando en ella todas las cualidades que suelen seducir a los amantes, pensé conseguir fácilmente que se enamorara de mí. Era entonces tan famoso y poseía tal fascinación por mi juventud y belleza que no podía temer un rechazo de cualquier mujer que se hubiera enamorado de mi [...]». ${ }^{24}$

«Lleno de amor por aquella joven, busqué la ocasión para conseguir su amistad, mediante íntimas y frecuentes conversaciones con el fin de inducirla más fácilmente al consentimiento de mis deseos. Para conseguir este propósito, mi interlocutor con el tío de Eloísa se sirvió incluso de algunos amigos suyos para que, a cualquier precio, me tomara como huésped en su casa, que estaba cerca de mi escuela, aduciendo como pretexto que los cuidados de la casa eran un obstáculo para mis estudios, además de gravarme con un gasto excesivo. Fulberto era muy ambicioso y deseaba que su sobrina progresase cada vez más en los estudios. Por estos dos motivos obtuve fácilmente su consentimiento y cuanto yo deseaba $[. ..] \gg_{\circ}{ }^{25}$

Eloísa, como casi todas las jóvenes de París, debía de estar secretamente enamorada de Abelardo, como dejan entreverlo las palabras que encontramos en la Epistola II: «¿qué esposa, qué virgen no te deseaba en secreto y no ardía de pasión al verte? ${ }^{26}$ De esta manera, cuando Abelardo se convierte en su preceptor, —con esta condición el ambicioso, pero

24 De esta fascinación singular que ejercía Abelardo, tenemos confirmación en el apasionado testimonio de Eloísa, donde en su segunda carta dice entre otras cosas: «¿Qué rey, qué filósofo podía igualar tu fama? ¿Qué región o ciudad o villa no deseaba verte? ¿Quién no corría a admirarte cuando aparecías en público y no te seguía con la mirada cuando altivo y radiante te alejabas? ¿Qué esposa, qué virgen no te deseaba en secreto y no ardía en pasión al verte?. Posees dos cosas sobre todo con las cuales podías conquistar el corazón de cualquier mujer: la gracia de tus versos y la fascinación de tus cantos. En esto no te ha superado nunca ningún filósofo». Eloísa, Epistola II, P.L. t. 178, p. 185.

25 «Erat quippe in ipsa civitate Parisius adolescentula quedam nomine Heloisae, neptis canonici cujusdam qui Fulbertus vocabatu, qui eam quanto amplius diligebat tanto diligentius in omnem qui poterat scientiam litterarum promoveri studereat. Que cum per faciem non esset infima, per habundantiam litterarum erat suprema. Nam quo bonum hoc litteratorie scilicet scientie in suprema. Nam quo bonum hoc litteratorie scilicet scientie in mulieribus est rarius, eo amplius puellam commendabat et in toto regno nominatissimam fecerat. Hanc igitur, omnibus circunspectis que amantes allicere solent, commodiorem censui in amorem mihi copulare, et me id facillime credidi posse. Tanti quippe tunc nominis eram et juventutis et forme gratia preminebant, ut quamcumque feminarum nostro dignarer amore nullam vererer repulsam[...]».

«In hujus itaque adolescentule amorem totus inflamatus, occasionem quesivi quam eam mihi domestica et cotidiana conversatione familiarem efficerem et facilius ad consensum traherem. Quod quidem ut fieret, egi cum predicto puelle avunculo, quibusdam ipsius amicis intervenientibus, qutinus me in domum suam, que scolis nostris proxima erat, sub quocumque procurationis precio susciperat, hanc videlicet occasionem pretendens, quod studium nostrum domestica amore familie cura plirium prepediret, ut impensa nimia nimium me gravaret. Erat autem cupidus ille valde atque erga neptim suam, ut amplius semper in doctrinam proficeret litteratoriam, plurimum stdiosus. Quibus quidem duobus facile ejus assensum assecutus sum et quod optabam obtinui, cum ille videlicet et ad pecuniam totus.inhiaret et eptim suam ex doctrina nostra aliquid percepturam crederet». Historia calamitatum, ed. cit., 280-294; 300-316.

26 «Que conjugata, quae virgo non concupiscebat absentem, et non exardebat in praesentem?». Eloísa, Epistola II, P.L. t. 178, p. 185. 
ingenuo Fulberto, le había concedido la hospitalidad-, se estableció rápidamente una intensa comunión de afectos entre el maestro y la discípula, ya fascinada y dominada enteramente por su personalidad:

«Primero nos unimos en la misma casa, después unimos los corazones. So pretexto de las lecciones, atendíamos más a nuestro amor y la intensidad del estudio nos ofrecía los lugares secretos que deseaba el amor. Una vez abiertos los libros nos ocupábamos más de las palabras amorosas que de las frases de los textos. Eran más los besos que las sentencias y mis manos acariciaban más los senos de la joven que los libros. Mientras, el amor se reflejaba en nuestros ojos y obnubilaba la lectura».27

Había nacido un amor que iba a convertirse en mito. Era un amor que iba a transformarse en drama y que atormentará durante toda la vida a los dos protagonistas, pero sobre todo, yo diría, que a Eloísa, que se consagrará a él con una dedicación absoluta y heroica y conservará siempre en su alma el recuerdo dedicado e indeleble.

Un primer presagio de la inminencia del drama se barrunta ya en la queja de los discípulos, a los que no escapa, se escapan pocas cosas a los ojos de los jóvenes, el estado de turbación y el tedio del maestro, hasta ayer brillantísimo y ahora tan apático y frío. Ya se corren las voces, ya se rumorea sobre las causas de un cambio tan repentino. La vox populi llega hasta los oídos del Fulberto que, primero hace oídos sordos a las insinuaciones: «difícilmente sospechamos cosas malas de las personas que nos son muy queridas, ni puede sustituir la innoble mancha de la sospecha en un gran amor. De aquí el famoso dicho de San Jerónimo: "A menudo somos los últimos en conocer los defectos de nuestra casa e ignoramos los vicios de los hijos y la mujer, mientras los vecinos van divulgándolos". ${ }^{28}$

$\mathrm{Al}$ final, como era inevitable, los dos amantes son descubiertos. Fulberto es presa del furor al sentirse humillado por su pupilo; Abelardo, destrozado por la vergüenza; Eloísa, en cambio, coherente con su convicción, jamás se arrepintió ni se avergonzó de su sentimiento. Experimentó solamente un dolor intenso, no por ella o por el dolor de su tío, sino por la deshonra y la humillación del amado. La joven Eloísa no se sintió culpable, mas, poco tiempo después de ser descubierto su secreto amor con el que era su preceptor, su maestro, su amante, le comunica, cum summa exultatione, ${ }^{29}$ con gran regocijo, que espera un hijo.

27 «Primo domo una conjungitur, postmodum animo. Sub occasione itaque discipline, amori penitus vaccabamus, et secreto seccessus, quos optabat, studium lectionis offerebat. Apertis itaque libris, plura de amore quam de lectione verba se ingerebant, plura erant oscula quam sententiae; sepius ad sinus quam ad libros reducebantur manus, crebrius oculos amor in se reflectebat quam lectio in scripturam dirigebat». Historia calamitatum, ed. cit., 332-339.

28 «Solemus mala domus nostre scire novissimi ac liberorum ac conjugum vitia, vicinis canentibus, ignorare». Stud. Hieronimus, Epistola CXLVII, 10; P.L. t. 22, p. 1203; C. S. E. L., 56, 327; cfr. História calamitatum, ed. cit., 373-375.

29 Abelardo, Historia calamitatum, ed. cit., 392-393. 
Después del nacimiento de Astrolabio,$^{30}$ así llamaron a su hijo, que tuvo lugar en Bretaña, a donde Eloísa llegó en secreto para evitar los infalibles cotilleos del ambiente parisino, Abelardo trató de aplacar las iras del ofendido canónigo Fulberto y está dispuesto a casarse con Eloísa:

«Preso de gran compasión por su indecible dolor y acusándose duramente, como si de una infame traición se tratara, por el robo que le hizo mi amor, me acerqué a aquel hombre suplicándole y prometiéndole cualquier reparación que hubiera pensado para mi culpa, asegurando que no debía causar asombro a quienquiera que hubiera experimentado la fuerza del amor y a quien recordase que, desde el comienzo del género humano, las mujeres habían llevado a la ruina incluso hombres eminentes. Y para mejor calmarle le ofrecí una satisfacción superior a la que esperaba, casarme con la joven que había seducido, pero haciéndolo en secreto para no perjudicar mi reputación $[\ldots] \gg .{ }^{31}$

Abelardo había echado sus cuentas y había prometido al enfurecido Fulberto el matrimonio con su sobrina. Pero se había olvidado de algo muy importante, Eloísa, que se opone con fuerza a su proyecto y defiende su oposición con un larga serie de argumentos que toma de las Sagradas Escrituras y de Cicerón, de San Jerónimo y de Séneca y recurre hasta al mismísimo Teofrastro y encuentra en estos lugares la fuerza suficiente para demostrar la absoluta «inconciliabilidad del ideal del filósofo con la pobre realidad del marido». ${ }^{32}$ El filósofo debe estar libre de preocupaciones familiares; su casa debe ser el templo de la sabiduría y no deben turbarla «los llantos de los niños, los cánticos de las nodrizas, las ideas y venidas del servicio, hombres y mujeres de la casa». ${ }^{33}$ Para no perturbar el plan de vida de Abelardo y no obscurecer su fama, Eloísa está dispuesta a un gran sacrificio: renunciará a convertirse en un esposa y seguirá siendo su oculta y fiel amante.

Abelardo escuchó, sin contradecirla, la larga y apasionada defensa disuasoria del matrimonio que había hecho Eloísa. Fue una dehortatio a nuptiis. No hizo caso. A partir de

30 El misterioso nombre de Astrolabio - nacido de las estrella - podríamos compararlo con el de Adeodato, el hijo de San Agustín, a quien la historia reservó la misma suerte que a Astrolabio: el silencio. Un silencio que resulta tanto más sorprendente si tenemos en cuenta la gran fama de sus padres. Abelardo dedicó a Astrolabio un poema que tituló Carmen ad Astrolabium. El texto está incompleto en P.L. t. 178, p. 1759. Sin embargo en 1859 apareció su texto íntegro debido a J. B. Haureaux, «Le poème adressé par Abelardà son fils Astrolabe», Notices et extraits des manuscrits de la Bibliothèque Nationale, Paris, XXXIV, 2, (1859), pp. 151-187.

31 «Tandem ego ejus immoderate anxietati admodum compatiens, et de dolo quem fecerat amor tanquam de summa proditione me ipsum vehementer acusans, conveni hominem supplicando et promittendo quamcumque super hoc emendationem ipse et constitueret, nec illi mirabile id videri asserens, quicumque vim amoris expertus fuisset, et qui quanta ruina summos quoque viros ab ipso statim humani generis ex ordio mulieres dejecerint memoria retineret. Atque ut amplius eum mittigarem supra quam sperare poterat, obtulit me ei satisfacere, eam scilicet quam corruperam mihi matrimonio copulando, dummodo id secreto fieret, ne fame detrimentum incurrerem». Historia calamitatum, ed. cit., 410-422.

32 F. Alessio, Abelardo, I protagonisti della storia universale, vol. IV, Milano, C. E. I., 1967, p. 441.

33 «[...] pueriles vagitus, nutricum qui hos mittigant nenias, tumultuossam familiae tam in viris in feminis turbam sustinere poterit?» Historia calamitatum, ed. cit., 472-475. 
aquí surge la ocasión para romper una vez más con la tradición que eleva el celibato al rango de estado ideal para el filósofo y para el teólogo, además de para el eclesiástico, y Abelardo era entonces clericus y canonicus, aunque se trataba probablemente de un título académico, conferido a los profesores de las escuelas catedralicias.

Al final el matrimonio se celebró, pero según los pactos establecidos debía permanecer en secreto «a fin de no perjudicar la reputación del maestro». Pero querer ocultar una unión que en sí misma constituye una reparación y que fue hecha ante testigos era, a todas luces, un proyecto bastante ingenuo. A Fulberto y a sus amigos nada les apremió tanto como gritar a los cuatro vientos la noticia del matrimonio. El viejo canónigo, a quien no le precupaba guardar la palabra que había dado, encontró una excusa para divulgar la noticia: como la ofensa había sido pública, la reparación debía también ser pública. Eloísa reacciona de modo violento. Quiere defender el honor de su amado y «jura y perjura que la noticia era absolutamente falsa, alsissimum esse». ${ }^{34} \mathrm{La}$ situación de Eloísa es muy violenta. Debe vivir en un ambiente totalmente hostil y Abelardo decide sustraerla de los malos tratos de su tío: «Informado de esta situación la mandé a una abadía de monjas, cerca de París, llamada Argenteuil, donde fue educada e instruida siendo muy joven y con excepción del velo, hice que tomase el hábito de religiosa en armonía con la vida monástica». ${ }^{35}$ El gesto fue interpretado como una especie de maniobra astuta de Abelardo que pretendía de esta manera liberarse de su esposa. Él quedaría libre y seguiría siendo el gran maestro de dialéctica, mientras su esposa estaría recluida en un convento. «Su tío y parientes pensaron que me había burlado de ellos y que metí a Eloísa en el convento para deshacerme de ella».

Los ingredientes para el drama estaban ahí. Sólo faltaba el desenlace. Fulberto el canónigo, sus parientes y amigos estaban indignados. Todo estaba servido. Faltaba la ocasión y la ocasión se presentó: «una noche [nos dice Abelardo], mientras descansaba en casa en una habitación retirada, uno de mis criados, corrompido a precio de oro, los indujo, y me hicieron sufrir la más brutal y vergonzosa de las venganzas, venganza de la que el mundo entero se enteró con estupefacción: me cortaron las partes del cuerpo con que cometí aquello de que se quejaban. Después emprendieron la fuga». ${ }^{36}$

Ante la conmoción del todo París, Abelardo «movido más por un sentimiento de vergüenza que por vocación, se decide a buscar la sombra de un monasterio». ${ }^{37}$ "Vestimos los dos al mismo tiempo el hábito religioso, yo en la abadía de San Dionisio, Eloísa en el

34 «illa autem e contra anathematizare et jurare quia falsissimum esse», ibidem, 269-570.

35 «Quod cum ego cognovissem, transmisi eam ad abbatiam quandam sanctimonialium prope Parisius, que Argenteolum appellatur, ubi ipsa olim puellula educata fuerat atque erudita, vestesque ei religionis que conversationi monastice convenirent, excepto velo, aptari feci et his eam indui». Ibidem, 573-578.

36 «Unde vehementer indignati et adversum me conjurati, nocte quadam quiescentem me atque dormientem in secreta hospicii mei camera, quodam mihi serviente per pecuniam corrupto, crudelissima ultione punierunt, et quam summa admiratione mundus excepiti, eis videlicet corporis mei partibus amputatis quibus id quod plangebant commiseram». Ibidem, 581-587.

37 «...] pudoris potiusquam devotio conversionis ad monastichorum latibula claustrorum compulit». Ibidem, 624-625. 
convento de Argenteuil». Y en una línea más arriba de su Historia calamitatum, nos dice Abelardo: «Eloísa, siguiendo mis órdenes con entera abnegación, ya había tomado el velo y entrado en un monasterio». Eloísa acepta la orden de Abelardo, entra en el monasterio y profesa antes que él porque estaba dispuesta a seguirlo aunque fuera hasta el infierno. ${ }^{38} \mathrm{De}$ esta manera ya no podrá ser suya, pero tampoco será de ningún otro. Eloísa era su mujer ante Dios y ante los hombres, pero él no podía ser su esposo según la carne. El lazo que subsistía no podía ser disuelto más que por la entrada común en el monasterio. Al ordenar a Eloísa que tomase el velo, Abelardo parece como si estuviese dudando de ella. Es verdad que lo hizo con «entera abnegación», pero ¿hubiera seguido a Abelardo si él hubiera sido el primero en entrar en la abadía de San Dionisio? Existe como una especie de reproche en estas palabras de Eloísa: «nuestra común entrada en religión que vos solo decidísteis». Eloísa, a pesar de todo, ante el altar en el que se ofrecía ella misma como víctima, no encuentra mejores palabras que las lamentaciones de Cornelia, tomadas de la Farsalia de Lucano: «iOh noble esposo, tan poco hecho para el himeneo!, ¿tenía mi suerte ese derecho sobre una cabeza colocada tan alto? ¿Qué criminal soy! ¿Debía casarme para hacer tu desgracia? Recibe en expiación ese castigo a cuyo encuentro quiero ir».39.

Una vez restablecido de sus heridas y con la misma fuerza que antes, a pesar de la oposición de muchos detractores, reemprende la enseñanza y sus luchas intelectuales. Vuelve a ser el maestro de siempre, pero ahora, según el testimonio de Otón de Frisinga, «más agudo y más sabio», ${ }^{40}$ como si la mutilación sufrida hubiera multiplicado en él la capacidad especulativa de su mente. Fruto de su enseñanza y de su estudio es el Tractatus de Unitate et Trinitate divina, ${ }^{41}$ el primer tratado teológico de Abelardo, en el que rompiendo con los moldes de la tradición, aplica a los enunciados de la fe, el método de la nueva ciencia, la dialéctica. Introduce el razonamiento humano y filosófico, mediante analogías. Quiere responder a las exigencias de los alumnos que le piden argumentos humanos y filosóficos. Quieren explicaciones y no aserciones, porque les parece inútil pronunciarse sobre las palabras sin entender su significado. Quieren entender primero, para poder creer después.

Unos años antes y dentro de un contexto distinto y con alumnos distintos, San Anselmo también había acudido a la dialéctica. San Anselmo hacía una teología en y para el monasterio. San Anselmo se dirigía a monjes que creían, que no ponían en duda la fe. Su diálogo no era tal, era un monólogo y por eso partía de la fe para llegar a la razón. Credo

38 «Aeque autem (Deus scit) ad Vulcania loca te properantem praecedere vel sequi pro iussu tuo minime dubitarem». Eloísa, Epistola II, P.L. t. 178, p. 186.

39 Lucano, Pharsalia, VIII, 94-98.

40 Otón de Frisinga, Gesta Frederici I, lib. I, cap. 47, ed. cit., p. 376.

41 Sobre este tratado de Abelardo nos han llegado dos redacciones. Una edición incompleta de la obra fue publicada por R. Stölzle con el título Abaelards 1121 zu Soissons verurteilter Tractatus de unitate et Trinitate divina, Freiburg i. Br., 1891. Después, H. Ostlender hace una edición íntegra de la obra y la titula, Peter Abaelard Theologia «Summi Boni» zum ersten Male vollständing herausgegeben, en Beiträge t. XXXV, 2-3, Münster, 1939. 
ut intelligam, nos dijo. Ahora el maestro de Palet, partiendo de una posición distinta, quiere llegar a la fe mediante la razón, por eso dice: Intelligo ut credam. El tradicional «creo para entender» se convertía ahora en «entiendo para creer», porque parecía responder de modo concluyente a todas las cuestiones. ${ }^{42}$

Los éxitos intelectuales siempre tienen un pero. Nunca se da la aceptación total por parte del que desde posiciones distintas y con puntos de mira distintos, piensa de otra manera. Abelardo supo mucho de esto. Sus éxitos siempre tuvieron una sombra. Ahora también. Las doctrinas defendidas por Abelardo y la introducción de la dialéctica en teología, provocaron la reacción violenta de algunos teólogos conservadores que ya en su día, en la escuela del viejo maestro Anselmo, en Laon, habían intentado torpedear la carrera de Abelardo. Aparecen ahora como entonces Alberico de Reims y Lotulfo de Lombardía. También entra ahora en escena el resentido Roscelino, antiguo maestro de Abelardo, que desafía al discípulo no a un duelo, sino a una disputa dialéctica pública. Abelardo aquí dio la callada por respuesta y ya sabemos porqué (cf. n. 6). Alberico y Lotulfo convencen al obispo de Reims y al legado pontificio para que convoquen un concilio en Soissons que condene las doctrinas que Abelardo expone en su Tractatus de Unitate et Trinitate divina.

El concilio se celebró en la primavera de 1121 y se desarrolló en un ambiente hostil a Abelardo, que corre el riesgo de ser apedreado como hereje por un grupo de fanáticos. El maestro acusado no tuvo la posibilidad de pronunciar una sola palabra en defensa propia, a pesar de la exhortación que el obispo de Chartres, Godofredo de Lèves, hizo a los jueces para que escucharan las explicaciones y tuviesen en cuenta, si procedía, las justificaciones del acusado. ${ }^{43}$

No tenemos las actas del concilio; así que no es posible establecer con precisión la motivación exacta de la condena. Pero si nos atenemos al testimonio de Otón de Frisinga, es válida la opinión que sostiene que la acusación era profesar y defender ideas sabelianistas. ${ }^{44}$ Por semejante acusación y por haber tenido «la osadía y presunción de leer en público su libro sin la aprobación del Romano Pontífice ni de la Iglesia», ${ }^{45}$ Abelardo es condenado, a

42 «Accedit autem mihi ut ad ipsam fidei nostre fundamentum humane rationis similitudinisbus disserendum primo me aplicarem, et quendam theologie tractatum De Unitate et Trinitate divina scolaribus nostris componerem, qui humanas et philosophicas rationes requirebant, et plus que intelligi quam que dici possent efflagitabant: dicentes quidem verborum superfluam esse prolationem quam intelligentia non sequeretur, nec credi posse aliquid nisi primitus intellectum [...]», Historia calamitatum, ed. cit., 690-698.

43 Nos dice Abelardo que, ante la propuesta del obispo de Chartres, sus adversarios replicaron alarmados: «O sapientis concilium, ut contra ejus verbositatem contendamus cujus argumentis vel sophismatibus
universus obsistere mundus non posset!». Ibidem, $817-819$.

44 «...] de sancta Trinitate docens et scribens, tres personas quas sancta Ecclesia non vacua nomina tantum, sed res distinctas suisque proprietatibus discretas, hactenus et pie credidit et fideliter caetera dixit: Sicut eadem oratio est propositio, assumptio et conclusio: ita in eadem essentia est Pater, et Filius et Spiritus Sanctus. Ob hoc Suessionis provinciali contra eum synodo, sub praesentia Romanae sedis legati congregata, [...] Sabellianus haereticus iudicatus, libros quos ediderat, propria manu ab episcopis igni dare coactus est nulla sibi respondendi facultate, eo quod disceptandi in eo peritia ab omnibus suspecta haberetur, concessa». Otón de Frisinga, Gesta Frederici I, lib. I, cap. 47, ed. cit., p. 377.

45 «Dicebat enim ad dampnationem libelli satis hoc esse debere quod nec romani pontificis nec Ecclesie auctoritate eum commendatum legere publice presumpseram [...]». Historia calamitatum, ed. cit., 848-851. 
propuesta de sus acusadores, a quemar, en pleno concilio, su tratado sobre la Trinidad y a ser recluido, como en una cárcel, en el monasterio de San Medardo donde, según la tradición, eran confinados los clérigos licenciosos y reos de delitos comunes.

Como era de esperar, la condena trajo consigo la impopularidad y la protesta unánime por parte de los estudiantes. El legado pontificio ordenó la liberación de Abelardo y sus restitución a la abadía de San Dionisio. Tampoco aquí encontró la paz porque, aparte de convertirse en objetivo de las iras de los monjes y del abad Adam por las duras críticas a sus corrompidas costumbres, — «La abadía estaba entregada a todos los desórdenes de la vida mundana. El abad ocupaba el primer lugar entre todos sólo por la corrupción y la indignidad de sus costumbres»; «[...] me rebelé más de una vez contra estos escandalosos desenfrenos, unas veces en privado, otras en público [...]»—, Abelardo suscitó un gran escándalo dentro de la abadía al defender que el fundador de la abadía real de San Dionisio no era, de hecho, Dionisio el Areopagita, discípulo de San Pablo, como se creía basándose en una antigua tradición recogida y defendida en los escritos hagiográficos de Hilduino. ${ }^{46}$ Esto era atentar contra lo más sagrado de la abadía y a los ojos de los monjes Abelardo se convertía, además, en «sacrílego».

Era demasiado para seguir viviendo allí. Esta situación le hace huir, pero obtiene del sucesor del abad Adam, que tan mal parado sale en la Historia calamitatum, una autorización para poder vivir fuera del claustro, extra claustra. Este abad es Suger o Sugerio, consejero de Luis VI de Francia y regente del reino. El nombre de este abad no aparece en la obra de Abelardo y, en cambio, tiene muchos puntos en común. Es, como Abelardo, un gran humanista, aparece como un hombre con temperamento intrépido e innovador. Y como Abelardo está de acuerdo en la necesidad de reformar el modo de vida de los monjes de la abadía de San Dionisio. El abad Siger llevará a cabo la reforma bajo la influencia de Bernardo de Claraval. Bernardo triunfará donde Abelardo había fracasado. Ésta es la primera confrontación entre dos hombres que la continuidad de su existencia va a oponer de modo dramático. Uno y otro ignoran todavía lo que sucederá después y Abelardo, ahora, se limita a hacer un balance negativo: «me hice odioso e insoportable a todos».

¿A dónde ir? El filósofo errante había probado casi todo: escuelas catedralicias, monasterios... ¿Sería capaz Abelardo de vivir en soledad? ¿Encontraría la paz precisamente allí, alejado, olvidado, en el silencio? Va a intentarlo. En compañía de algunos de sus discípulos busca refugio en un lugar solitario cerca de Nogent, a orillas del río Ardozon y allí es donde funda el El Paráclito, oratorio dedicado al Espíritu Santo y se convertirá en uno

46 Cfr. Sancti Dionysii Vita iussu Ludovici Pii ab Hilduino scripta, P.L. t. 106, pp. 14-24 y Passio Sanctissimi Dionyssii, P.L. t. 106, pp. 24-50. La Vita Sancti Dionysii se encuentra también en M.G. H., Epp. Carol.aevi, III, pp. 327-335. En realidad Hilduino - que fue abad de San Dionisio en la primera mitad del siglo IX y tradujo por primera vez al latín el Corpus Areopagiticum que una embajada del Basileus bizantino Miguel II trajo y entregó solemnemente a Ludovico Pío en 827- confundió o deliberadamente identificó a San Dionisio mártir, primer obispo de París, muerto en el siglo III, con Dionisio Areopagita, muerto en el siglo I. Cfr. S. M. Crosby, The Abbey of St. Denis, Yale University Press, 1942, p. 42ss; R. J. Loenerzt, «La legende Parisienne de Saint-Denys l'Aréopagite», Analecta Bollandiana, 69 (1951), p. 217ss. 
de los monasterios más famosos de Francia. ¿Fue entonces cuando se ordenó sacerdote de manos de Atón de Troyes? Sabemos que fue este obispo quien le autorizó la construcción del oratorio y sabemos también que este obispo le permitió enseñar, scholam constituere, en su diócesis. Por fin la paz llegó para Abelardo. Goza de esta paz durante un período de tiempo. Y si la paz es tranquilitas ordinis, como diría San Agustín, Abelardo, en la paz encontró la tranquilidad, el orden también. Esta misma paz, como tranquilidad del orden, le lleva a dedicarase con intensidad a lo que el maestro sabe hacer como nadie, enseñar.

Dicen que la alegría dura poco en caso del pobre. Y pobre era Abelardo en cuestión de paz, de tranquilidad... Una vez descubierto el refugio del maestro, se rompió la tranquilidad porque los discípulos fueron llegando de todas partes. Tenían hambre y sed, y Abelardo era el que podía satisfacer sus necesidades, en principio espirituales, como ganas de saber, de aprender directamente del maestro, pero a las que siguieron las otras, las corporales, la sed y el hambre, los inconvenientes, la falta de descanso. Abelardo nos describe así en su Historia calamitatum esta acontecimiento: «[...] comenzaron a llegar de todas partes, abandonando ciudades y pueblos, para establecerse en aquella especie de desierto y, en lugar de grandes casas construyeron pequeñas celdas $y$, en lugar de comidas delicadas se alimentaban de hierbas silvestres y de pan de mala calidad, y prefirieron lechos de borra y paja a blandas camas [...]». ${ }^{47}$ Alguien ha dicho que esos momentos constituyen «el episodio más conmovedor en la historia del pensamiento medieval». ${ }^{48}$

Abelardo volvía a convertirse en el punto de mira de todos los ojos jóvenes. Volvió a ser el personaje que los fascinaba, el que decía algo. Como antaño, también ahora, es el centro de atención de la intelectualidad francesa. Y si en su primera juventud tuvo muchos problemas, los que va a tener ahora no van a ser menores. La envidia de sus adversarios los pone en movimiento y le acusan de hereje al dedicar su oratorio al Espíritu Santo despreciando así, decían, la tradición. El grito de hereje era unánime entre sus enemigos y a esto añadieron las calumnias de todo tipo. ${ }^{49}$

47 «Quod cum cognovissent scolares, ceperunt undique concurrere, et relictis civitatibus et castellis solitudinem inhabitare, et pro amplis domibus parva tabernacula sibi construere, et pro delicatis cibis herbis aggrestibus et pane cibario victitare, et pro millibus stratis culmum sibi et stramen comparare, et pro mensis glebas erigere [...]». Historia calamitatum, ed. cit., 1044-1050.

48 C. Ottaviano, Pietro Abelardo. La vita, le opere, il pensiero. Roma, s. a. [1931], p. 41.

49 En la Historia calamitatum, 1170-1186, Abelardo responde a los que le acusaban de haber roto con la tradición al dedicar su oratorio al Espíritu Santo: «Si consideramos atentamente el testimonio del Apóstol y la misma acción del espíritu, parece más conveniente que el templo sea dedicado al Espíritu Santo que a las otras Personas divinas. Entre las tres Personas, el Apóstol sólo asigna al Espíritu Santo en particular un templo especial cuando escribe en la primera carta a los Corintios (I Cor., VI, 17-19): «No sabéis que vuestros cuerpos son templos del Espíritu Santo, que está en vosotros y, que os ha sido dado por Dios, y que no os perteneceis?» ¿Quién ignora, además, que los sacramentos que se administran en la Iglesia y son fuentes de divjnos favores, son atribuidos de modo particular a la acción de la gracia divina, es decir, a la acción del espíritu santo? En el bautismo, por virtud del agua y del Espíritu Santo, renacemos a la vida espiritual y desde aquel momento y por primera vez nos constituimos en el templo especial de Dios. En la confirmación recibimos la gracia del Espíritu con la cual el templo de Dios es adornado y consagrado. ¿Qué tiene de extraño si dedicamos un templo de piedra a aquella Persona de la Trinidad, a la que el Apóstol atribuye un especial templo espiritual?» 
Como caballero andante que va de aventura en aventura, Abelardo abandona la tranquila soledad de El Paráclito, renuncia a la enseñanza y acepta el cargo de abad del monasterio bretón de San Gildas. No iba a ser ésta una vida sin sobresaltos y llena de tranquilidad, precisamente: «Me encontraba [escribe Abelardo] en un país bárbaro, donde se hablaba un dialecto que me era desconocido, entre monjes cuya vida corrupta y desenfrenada era de todos conocida y en medio de una población salvaje y sin ley. Y como el que sabe que tiene sobre su cabeza un espada que pende sobre ella y vive aterrorizado y se lanza a un precipicio evitando una muerte, pero encontrando otra, así me pasó a mí que, huyendo de un peligro me metí en otro. $Y$ allí al borde del ruidoso Océano, desde aquel remoto trozo de tierra, a menudo repetía en mis oraciones las palabras del Salmo: "Desde el confín de la tierra, clamo a ti, Señor, cuando se angustia mi corazón". 50

Abelardo trató de reformar el monasterio, que, después de siglos de esplendor, había llegado ahora a un estado de gran decadencia moral y material. No corrían los tiempos del Fundador, tampoco estábamos en el siglo VI y Abelardo hizo una llamada enérgica a los monjes, que casi todos vivían con sus concubinas, para que tuvieran presente las obligaciones que les imponía su profesión religiosa. Se opone también con todas sus fuerzas a las injerencias y a las usurpaciones del prepotente feudatario del lugar. El resultado no se hizo esperar: un día encontró veneno en el cáliz con el que debía celebrar la misa y otro, los esbirros del tirano intentaron asesinarlo.

Mientras se debatía entre los peligros de dentro con los monjes y de fuera de su monasterio con el señor feudal, recibe una noticia desagradable: el abad Siger, basándose en antiguos documentos, ${ }^{51}$ reivindica la posesión del monasterio de Argenteuil como perteneciente a la abadía de San Dionisio y había decidido expulsar por la fuerza, violenter expelleret, a las monjas que formaban una pequeña comunidad con Eloísa como priora.

Conmovido por el espectáculo de «aquellas infelices que andaban prófugas y errantes de un lugar a otro», ${ }^{52}$ Abelardo, hacia finales del 1129, vuelve de Bretaña y ofreció a Eloísa y a su comunidad religiosa el oratorio de El Paráclito y consigue que la donación sea ratificada con una bula del Papa Inocencio II el 28 de noviembre de $1131 .{ }^{53}$

50 «Terra quippe barbara et terre lingua mihi incognita erat, et turpis atque indomabilis illorum monachorum vita omnibus fere notissima, et gens terre illius inhumana atque incomposita. Sicut ergo ille, qui imminente sibi gladio perterritus in precipitium se collidit et ut puncto temporis mortem unam differat aliam incurrit, sic ego ab uno periculo in aliud scienter me contulit; ibique ad horrisoni undas Occeani, cum fugam mihi ulterius terre postremitas non preberet, sepe in orationibus meis illud revolvebam: "A finibus terre ad te clamavi, dum anxiaretur cor meum"». Historia calamitatum, ed. cit., 1243-1254.

51 Sobre la autenticidad de estos documentos y sobre otros medios usados por el abad Siger para obtener del rey Luis IV y del Pontífice Honorio II la devolución de Argenteuil a San Dionisio, algunos historiadores han manifestado sus reservas, Cfr. J. Mabillon, Annales Ordinis Sancti Benedicti, t. VI, Paris, 1739, p. 172ss; E. McLeod, Heloise, p. 83.

52 «Que cum diversis locis exules dispergerentur, oblatum mihi a Domino intellexi occasionem qua nostro consulerem oratorio». Historia calamitatum, ed. cit., 1310-1313.

53 El documento pontificio del que existe el original conservado en la Biblioteca de Châlons-sur-Marne, fue publicado por Ch. Lalore, Cartulaire de l'Abbaye du Paraclet, Paris, 1878, pp. 1-3. 
De esta manera Abelardo y Eloísa vuelven a encontrarse, después de una separación de diez años, en aquel oratorio solitario a orillas del Arduzon. No se dice nada de los sentimientos que suscitó en él este encuentro. Pero por más que su carácter hubiera cambiado, al menos en recuerdo del tiempo pasado se despertaría en él ante la presencia de la que era todavía la misma incomparable señora que él había conocido tan íntimamente. En cuanto a ella, aunque no haya dejado memoria del encuentro, no es difícil figurarse qué cantidad de sentimientos la habrán acometido al volver a ver al hombre que jamás había dejado, en todos aquellos años, de ocuparle el corazón y el pensamiento y que en vano había suspirado por su presencia. ${ }^{54}$

Abelardo nos ha dejado un retrato primoroso de Eloísa en este período en una página de la Historia calamitatum. Está hecho con gran finura y sensibilidad y nos la describe como una perfecta religiosa. Sin embargo no llega, o no quiere, describir el drama interior que vivía Eloísa:

«El Señor concedió tanta gracia a los ojos de todos, a nuestra hermana Eloísa, que era abadesa de la comunidad, que los obispos la querían como a una hija, los abades como una hermana y los laicos como una madre; y todos indistintamente, admiraban su piedad, su prudencia, su incomparable paciencia y dulzura. Y cuando menos se hacía ver, para dedicarse más libremente a las meditaciones sacras y a la oración en la intimidad de su celda, tanto más vehementemente la gente de fuera reclamaba su presencia y sus enseñanzas espirituales». ${ }^{55}$

Todo esto es cierto, pero es algo externo. El cuadro que pinta Abelardo es muy bonito, pero faltan las pinceladas que nos lleven hasta el interior de Eloísa. ¿Se le olvidaron a Abelardo? ¿No supo escrutar la realidad interior de su amada? Será la propia Eloísa la que en su segunda carta le descubra todo lo que llevaba dentro. Es una obra maestra de la literatura amoroso de la Edad Media y que sólo una crítica insensible a los hechos del espíritu ha podido sospechar de inautenticidad. ${ }^{56}$ En esta carta Eloísa confía a Abelardo, que ya había regresado a la abadía de San Gildas, todo su drama interior, desnudando su alma envuelta todavía en la espiral de la antigua pasión:

«Si debo confesarte toda mi debilidad y la miseria de mi pobre alma, te diré que no logro encontrar en mi corazón un arrepentimiento capaz de aplacar a Dios, que, por el ultraje del que fuiste víctima, yo siempre califico como de gran crueldad [...].

54 Cfr. E. McLeod, Heloise, p. 101.

55 «Tanta autem gratia in oculis omnium illi sorori nostre, que ceteris preerst, Dominus annuit, ut eam episcopi quasi filiam abbates quasi sororem, laici quasi matrem diligerent; et omnes pariter ejus religionem, prudentiam, et in omnibus incomparabilem patiencie mansuetidinem ammirabantur. Que quanto rarius se videri permittebat, ut scilicet clauso cubiculo sacris meditationibus atque orationibus purius vaccaret, tanto aedentius ejus presentiam atque spiritalis colloquii, monita hii qui foris sunt efflagitabant». Historia calamitatum, ed. cit., $1331-1340$.

56 Cfr. E. Gilson, Héloïse et Abélard, Paris, J. Vrin, 1948, p. 148. 


\begin{abstract}
Aquellos placeres de amor que gozamos juntos han sido siempre tan dulces para mí que no logro ni arrepentirme ni borrar el recuerdo. A cualquier sitio que me vuelva, aparecen siempre ante mis ojos con toda su sugestión, e incluso en el sueño me persiguen con su ilusión. Hasta en los momentos solemnes de la Misa, cuando más pura debe ser la oración, los obscenos fantasmas de aquellos placeres atan de tal manera mi alma que me entrego más a aquellas torpezas que a la oración. Qué infeliz soy y qué derecho tengo a repetir el lamento de aquel alma que gemía: "¡Infeliz de mí!, ¿quién me librará de este cuerpo de muerte? Me llaman casta porque no pueden ver mi interior; llaman virtud a la castidad de mi cuerpo, cuando la virtud no es algo del cuerpo sino del alma. Soy objeto de alabanza a los ojos de los hombres, pero no tengo ningún mérito ante Dios, que es el que escruta los corazones y lee el interior de cada uno". ${ }^{57}$
\end{abstract}

Esta desolada confesión debió inquietar profundamente a Abelardo y le indujo a acelerar su madurada decisión de abandonar el gobierno de la turbulenta abadía de San Gildas y dedicarse a la dirección espiritual de la comunidad de El Paráclito y sobre todo de Eloísa, consciente de que sólo él podría inducirla a olvidar su pasado de culpa y a elevar y sublimar en Dios su amor terreno. Que lo consiguiera es algo que debemos poner en duda..$^{58}$ Sin embargo, en las cartas sucesivas, el drama que vive Eloísa se convierte en algo marginal, luego se silencia y ocupan su lugar argumentos de dirección y problemas de exégesis bíblico-teológica.

Después de este paréntesis que Abelardo vivió en El Paráclito, junto a Eloísa, sintió nuevamente la pasión de la enseñanza que llevaba dentro y se dejó dominar. Volvió a París y volvió a formar escuela, scholam constituere, volvió a la dialéctica allí donde había gozado de sus éxitos juveniles, en la colina de Santa Genoveva y por allí pasaron Arnaldo de Brescia y Juan de Salisbury, que en su Metalogicon recuerda que hacia 1135, cuando tenía 15 ó 16 años, cum primum adolescens admodum..., aprendió en París los primeros elementos de la dialéctica, escuchando «al peripatético Palatino, que ahora dominaba sobre la colina de Santa Genoveva, doctor ilustre y admirado de todos». ${ }^{59}$

Esta vuelta de Abelardo a la enseñanza estuvo acompañada, como siempre, de gran popularidad y de adhesiones entusiastas de los estudiantes. Sus «atrevimientos teológicos» iban a provocar, una vez más, la condena y la repulsa. Esta vez la condenación iba a ser definitiva.

En el 1138-39 un abad cisterciense, Guillermo de Saint-Thierry envió una carta alarmista y una larga Disputatio adversus Petrum Abaelardum al obispo Godofredo de Chartres, en otro tiempo discípulo de Abelardo y ahora legado papal de Francia, y a Bernardo de Claraval, donde denunciaba las doctrinas abelardianas como infectas de peligrosas novedades tendentes a racionalizar y a destruir los dogmas de la fe: «Pedro

57 Eloísa, Epistola IV, P.L. t. 178, pp. 196-198; ed. Muckle, Mediaeval Studies, XV (1953) pp. 80-81

58 E. Gilson, op. cit., pp. 83ss y 105 ss.

59 J. de Salisbury, Metalogicon, lib. II, cap. 10; P.L. t. 199, p. 867; ed. Webb, p. 78. 
Abelardo nuevamente vuelve a enseñar y a escribir novedades». Sus libros cruzan los mares y pasan los Alpes y sus «novedades sobre la fe y los dogmas se extienden por provincias y reinos $[. ..] \gg .^{60}$

El grito de alarma fue escuchado por Bernardo de Claraval, no en balde era considerado como «árbitro de la Cristiandad», por haber contribuido a arreglar el cisma del antipapa Anacleto. Estamos ante uno de los momentos más dramáticos del pensamiento medieval. Dialéctica y mística van a enfrentarse cara a cara. Va a establecerse un duelo ideológico entre el maestro Abelardo y el abad Bernardo. Representan dos ideologías encontradas, dos situaciones que más pronto o más tarde debían aclararse. Dialéctica y mística estaban ahí. La dialéctica representaba la novedad y era seguida con entusiasmo por los jóvenes estudiantes de París, que pedían razones para robustecer su fe, para interrogar...; la mística representaba la tradición y tenía sus seguidores, que veían con malos ojos a los «nuevos maestros». Abelardo se propone abordar los aspectos esenciales de la fe por el camino del razonamiento dialéctico. No es que piense negar que la fe reposa sobre una revelación, pero su manera de ser le induce a confiar en el elemento intelectual, por lo menos en «los preliminares de la fe». Bernardo se sitúa lo más lejos posible de todo intelectualismo. Para él lo primero es el amor, no el razonamiento. El amor es el que crea la fe. En unas palabras podíamos resumir sus posiciones: la tendencia de Abelardo consistía en llamar y considerar como «problema» lo que, para Bernardo de Claraval, era un «misterio».

El monje Bernardo no quedó impasible ante la misiva recibida y comenzó a mover hábilmente los hilos hasta lograr la caída de su adversario. Se introduce en el campo de su enemigo y se dirige a los estudiantes y profesores de las escuelas de París, a los que intenta convencer de los peligros que encierran las novedades del siglo. La dialéctica era un mal y los «dialécticos» los enemigos de la fe. Después de este discurso, ${ }^{61}$ trata de concertar una entrevista con el propio Abelardo. El encuentro se produce y el dialéctico y el místico entablan un diálogo. La paz no se logra. Sus posiciones eran demasiado divergentes. Abelardo despreciaba olímpicamente a su interlocutor. No era un dialéctico, tampoco un intelectual. Los caminos de uno y otro no llegaron a encontrarse; al contrario, se separaron más. La dialéctica había convertido a Abelardo en hombre odioso y a Bernardo le escandalizó más que sus tesis, la actitud arrogante de Abelardo. Los conocimientos teológicos del dialéctico eran profundos, pero estaban infectados de una filosofía mundana, creía el monje.

A partir del encuentro la ruptura se hace irrestañable, Bernardo comienza un género epistolar cargado de insultos y difamaciones contra su adversario. Dirige sus cartas al Papa, al conjunto de la curia romana, a cardenales, a obispos, a antiguos monjes, a canónigos:

60 Guillelmi Abbatis S. Theodorici, Epistola ad Goufridum Garnotensem episcopum et Bernardum abbatem Clarevallensem, P.L. t. 182, p. 531. La Disputatio en P.L. t. 180, p. 249ss.

61 Sobre la temática de aquel discurso que lleva por título Sermo ad Clerigos de conversione, cfr. ed. crít., de L. Leclerq, Sancti Bernardi Opera, vol. IV, Romae, 1966, p. 69ss. A. Babolin, Le lettere di Bernanrdo di Chiaravalle contro Pietro Abelardo, Padova, Liviana, 1969, p. 25ss. 
«Maestro Pedro Abelardo, monje sin regla, prelado sin cargo, no observa ninguna ley y no le retiene ningún orden [...]. Herodes por dentro, Juan Bautista por fuera [...], fue condenado en Soissons [...], pero su nuevo error es peor que el primero», dice su carta 193 dirigida a Ivo de Chartres y a su amigo Gerardo Caccianemici, que será más tarde el papa Lucio $\mathrm{II}_{0}{ }^{62}$ Compara a Abelardo con el antipapa Anacleto: «Después de Pedro el León, he aquí Padre - el dragón». Y en una carta que dirige al Papa, vuelve a utilizar la imagen del león y del dragón y subraya con habilidad la amistad que une a Pedro Abelardo con Arnaldo de Brescia: «Maestro Pedro y este Arnaldo, peste de la que librásteis a Italia, se han aliado y se levantan contra el Señor y contra Cristo». ${ }^{63}$

Abelardo estaba desconcertante y, al mismo tiempo, muy dolorido con la actitud hostil de Bernardo y, deseando terminar esta polémica, con un gesto que provenía de su pasión por la dialéctica y siguiendo, en este caso, el mal consejo de un grupo de discípulos capitaneados por Arnaldo de Brescia, osó desafiar al abad Claraval y suplica al arzobispo de Sens, Enrique Sanglier, poder defender su propia doctrina en una disputa pública ante la asamblea de obispos y teólogos que iban a reunirse en Sens, en la octova de Pentecostés y con motivo de la solemne exposición de las reliquias de la catedral.

Pero Bernardo, reticente a aceptar el desafío, porque sabía que no podía competir con el mejor de los dialécticos y porque no estaba de acuerdo en que se discutiera la verdad de la fe, consiguió, con gran habilidad y astucia y valiéndose de su gran influencia, transformar la asamblea en concilio y de esta manera poder conseguir la condenación solemne de su antagonista. La trampa está puesta. Había que esperar a que llegara la presa.

Abelardo había soñado con este día. Deseaba ardientemente exponer su doctrina ante una asamblea solemne donde estuvieran presentes la flor y nata de la intelectualidad del momento. Ése era su público. Allí estarían todos: obispos, clérigos y laicos, monjes y prelados. Pero Abelardo no sabía que su presencia se debía a una invitación personal que les había hecho el propio Bernardo con un fin bien distinto al que él creía.

Era el 2 de junio de 1140 y como estaba previsto la asamblea conciliar se inauguró. Ese domingo del mes de junio transcurrió entre ceremonias religiosas: exhibiciones de reliquias y oficios litúrgicos. Al final del día Bernardo se reúne con los prelados en sesión privada para examinar las proposiciones extraidas por Guillermo de Saint-Thierry de la obra de Abelardo. La lista de proposiciones condenables iba creciendo y la heterodoxia de Abelardo se veía por todas partes. Al final, diecinueve proposiciones iban a ser propuestas como heterodoxas y por lo tanto se declararían heréticas en la sesión plenaria de la asamblea, convertida ya en concilio o pseudo-concilio o en un simulacro de concilio, al decir de Berengario, discípulo del acusado.

Lo que Abelardo pensó iba a ser una tribuna ideal para defender sus doctrinas con sus métodos, se convirtió de pronto en un concilio donde se le acusaba y sólo se le iba a pedir humildad para aceptar las enmiendas y corregir su Teología y responder, si lo creía

62 S. Bernardo, Epistola 193; P.L.t. 182; la carta a Gerardo Caccianemici lleva el título número 332.

63 Ibidem, Epistola 330. 
conveniente, a las acusaciones que le hicieran. De antemano Abelardo estaba condenado. La tribuna ideal donde se veía siendo el ponente indiscutible, se había convertido en un tribunal parcial que iba a distribuir «justicia», cuando el acusado ya estaba condenado. El ponente no era él, sino Bernardo de Claraval, su enemigo. La mística hacía callar a la dialéctica y la condenaba por herética. $\mathrm{La}$ «santa» ignorancia y el fanatismo vencen a la razón y a la tolerancia. Abelardo que creía haber llegado el día en que, por fin, los intelectuales iban a ser los espectadores privilegiados del torneo teológico más importante del siglo, se vio cogido dentro de una red de la que no podía salir. No iba a ser como él pensaba. Es verdad que no se ajustaba a lo que había pedido al arzobispo Enrique Sanglier, pero Abelardo nunca pensó que su adversario iba a ir por esos derroteros. En ningún momento pasó por su mente que pudiera ser otro el orador. Él era el mejor de los dialécticos, el que mejor manejaba este arte. La tribuna tenía que ser ocupada por él y, además, no habría acusados y tampoco heréticos que fueran condenados. Únicamente quería dejar clara una cosa: la fuerza y el valor de la dialéctica eran compatibles con la fe.

Ante este lance imprevisto, Abelardo rechazó el debate que él mismo había solicitado. Se niega a responder a los requerimientos del monje. Apela al Papa. Abandona la asamblea y emprende el camino de Roma, donde nunca llegará, creyendo encontrar la paz ante tanta afrenta, y volver a ser otra vez el profesor de Santa Genoveva, el maestro de París aclamado por los estudiantes [...] No iba a ser fácil. La carrera del más brillante de los profesores del siglo XII ya había sido truncada por un monje que prefería el púlpito a la cátedra; lo místico a lo intelectual; el gusto sapiencial al saber científico; la posesión de la gracia mística, al aparato intelectual para el cultivo del espíritu; la interpretación de la teología como sabiduría, a la teología considerada como ciencia; la contemplación desconfiada de la inteligencia, a la actividad intelectual que la necesita.

Sin duda que durante todo este tieinpo Abelardo pensó, más que en nadie, en Eloísa. ¿Qué diría de su abandono? ¿Por qué le condenaban? ¿Para qué han montado todo ese teatro? ¿Será verdad que es hereje? Esta pregunta no era capaz de responderla afirmativamente. No podía ser. Imposible. ¿Le escucharían en Roma? ¿Convencerá a las «eminencias» y al Papa de que su doctrina no es heterodoxa y de que él no es un hereje? Mientras Eloísa trataba de buscar explicaciones a algo que objetivamente no tenía ninguna y como para sacarle de toda posible duda, le llega una carta de Abelardo, la última, que es una profesión de fe tan clara, tan precisa como la hubiera querido tener en sus manos o escucharla públicamente de sus propios labios el censor más exigente. Lo que Abelardo negó primero al abad de Claraval se lo entrega ahora a la abadesa de El Paráclito y confiesạ su fe en ella:

«Eloísa, hermana mía, antes tan querida en el siglo, ahora más querida aún en Jesucristo: la Dialéctica me ha hecho odioso al mundo. Dicen los corruptores perversos, cuya sabiduría es perdición, que soy un gran dialéctico, pero que me aparto mucho de la doctrina de San Pablo. Reconocen la clarividencia de mi talento, pero me niegan la pureza de la fe cristiana, y creo que juzgan como personas desorientadas por la opinión más que como personas instruidas por la experiencia». 
«No quiero ser filósofo si para ello tengo que rebelarme contra Pablo; no quiero ser Aristóteles si para ello tengo que alejarme de Cristo [...]».

Creo en el Padre, en el Hijo y en el Espíritu Santo, un solo Dios por naturaleza, el verdadero Dios en quien la Trinidad de las personas no causa ningún perjuicio a la Unidad de la sustancia. Creo que el Hijo es igual al Padre en todo [...]. Testifico que el Espíritu Santo es igual y consustancial en todo al Padre y al Hijo[ ...]».

«Ésta es la fe en que vivo y de la que saca fuerza mi esperanza [...]». ${ }^{64}$

El filósofo que siempre buscó la libertad para comunicar se había convertido en un disidente de la sociedad establecida. El que prefirió la filosofía a la carrera militar, buscando en la dialéctica lo que pedían a gritos los estudiantes, razones, argumentos válidos, no sólo basados en la autoridad, es condenado como hereje porque no se ajusta a las normas que alguien caprichosamente ha establecido. El que renunció a la primogenitura para convẹrtirse en Maestro de muchos alumnos que en una época en la que se comenzaba a poder pensar libremente, donde existían múltiples escuelas, donde el alumno podía escoger libremente y donde Aristóteles había hecho su segunda entrada con la Logica nova, ahora, al final, se le niega la libertad, mejor, se le manipula la libertad y, Abelardo que entendía la libertad en un sentido pleno, sin tapujos, y que necesitó siempre de ella, que la usó porque estaba convencido de que sin libertad no se podía hacer filosofía, renuncia ahora a manifestarse «libremente». Los que le tacharon de hereje por no hacer lo que ellos querían, y como ellos querían, tuvieron que contentarse con el silencio del Maestro de París, porque-sin libertad dialéctica tampoco hay filosofía y, algo que sus enemigos no entendieron, sin libertad no - hay teología y no hay fe, y en el siglo XII nuestro Maestro lo fue de filosofía, de teología $\mathrm{y}$ de fe.

\footnotetext{
64 Abelardo, Epistola XVII; P.L. t.178, pp. 375-378.
} 